ECLIPSE $^{11}$ and the NIH funded COPDGene Project.

It is not essential to solve the dilemma of whether the term COPD expresses correctly the protean clinical presentations of the same disease or that it combines different clinical entities, but it is necessary to realise that there are needs and research opportunities in an area that is largely unknown. The words "expiratory airflow limitation" expresses our present inaccuracy in differentiating increased airway resistance from increased lung compliance. ${ }^{27}$ HRCT studies have shown that at least two radiological patterns exist in which either airway obstruction or emphysematous destruction predominate. Ogawa and colleagues ${ }^{2}$ have convincingly demonstrated that, regardless of expiratory airflow limitation, the different pathological changes seen in vivo by HRCT are brought by people with different body habits. Let us jump over the hindering barrier of airflow limitation and explore the COPD world beyond!

Competing interests: None.

Thorax 2009;64:2-4. doi:10.1136/thx.2008.106674

\section{REFERENCES}

1. Burrows B, Fletcher CM, Heard BE, et al. The emphysematous and bronchial types of chronic airways obstruction. A clinicopathological study of patients in London and Chicago. Lancet 1966;87:830-5.
2. Ogawa E, Nakano $Y$, Ohara $T$, et al. Body mass index in male patients with COPD: correlation with low attenuation area on CT. Thorax 2009;64:20-25.

3. Kitaguchi Y, Fujimoto K, Kubo K, et al. Characteristics of COPD phenotypes classified according to the findings of HRCT. Respir Med 2006;100:1742-52.

4. Makita H, Nasuhara Y, Nagai K, et al. Characterisation of phenotypes based on severity of emphysema in chronic obstructive pulmonary disease. Thorax 2007;62:932-7.

5. Lee YK, Oh YM, Lee JH, et al. Quantitative assessment of emphysema, air trapping, and airway thickening on computed tomography. Lung 2008:186:157-65

6. Pistolesi M, Camiciottoli G, Paoletti $\mathbf{M}$ et al. Identification of a predominant phenotype of COPD in clinical practice. Respir Med 2008;102:367-76.

7. Madani A, Zanen J, de Maertelaer V, et al. Pulmonary emphysema: objective quantification at multidetector row CT. Comparison with macroscopic and microscopic morphometry. Radiology 2006;238:1036-43.

8. Nakano Y, Wong JC, de Jong PA, et al. The prediction of small airway dimensions using computed tomography. Am J Respir Crit Care Med 2005;171:142-6.

9. Gelb AF, Hogg JC, Müller NL, et al. Contribution of emphysema and small airways in COPD. Chest 1996;109:353-9.

10. Nishimura K, Izumi T, Tsukino M, et al. Dyspnea is a better predictor of 5-year survival than airway obstruction in patients with COPD. Chest 2002; 121:1434-40.

11. Vestbo J, Anderson W, Coxson HO, et al. Evaluation of COPD longitudinally to identify predictive surrogate end-points (ECLIPSE). Eur Respir J 2008;31:869-73.

12. Wedzicha JA. The heterogeneity of chronic obstructive pulmonary disease. Thorax 2000:55:631-2.

13. Friedlander $\mathbf{A L}$, Linch $\mathrm{D}$, Dyar $\mathrm{LA}$, et al. Phenotypes of chronic obstructive pulmonary disease. COPD: J Chronic Obstructive Pulm Dis 2007:4:355-84.
14. Vestbo J. COPD, diagrams and traditions: time to move on? Thorax 2008;63:755-6.

15. Rennard SI, Vestbo J. The many "Small COPDs": COPD should be an orphan disease. Chest 2008;134:623-7.

16. Reilly JJ. COPD and declining $\mathrm{FEV}_{1}$ - time to divide and conquer. N Engl J Med 2008;359:1616-18.

17. de Marco R. What evidence could validate the definition of COPD? Thorax 2008;63:756-7.

18. Burge PS. Euroscop, Isolde, and the Copenhagen City Lung Study. Thorax 1999:54:287-8.

19. Calverley PM, Anderson JA, Celli B, et al. Salmeterol and fluticasone propionate and survival in chronic obstructive pulmonary disease. N Engl J Med 2007;22:356:775-89

20. Tashkin DP, Celli B, Senn S, et al. A 4-year trial of tiotropium in chronic obstructive pulmonary disease. N Engl J Med 2008;359:1548-54.

21. Nakano Y, Muro S, Sakai H, et al. Computed tomographic measurements of airway dimensions and emphysema in smokers. Correlation with lung function. Am J Respir Crit Care Med 2000; 162:1102-8.

22. Hogg JC, Macklem PT, Thurlbeck WM. Site and nature of airways obstruction in chronic obstructive lung disease. N Engl J Med 1968;278:1355-60.

23. Orlandi I, Moroni C, Camiciottoli G, et al. Chronic obstructive pulmonary disease: thin-section CT measurement of airway wall thickness and lung attenuation. Radiology 2005;234:604-10.

24. O'Donnell RA, Peebles C, Ward JA, et al. Relationship between peripheral airway dysfunction, airway obstruction, and neutrophilic inflammation in COPD. Thorax 2004:59:837-42.

25. Croxton TL, Weinman GG, Senior RM, et al. Clinical research in chronic obstructive pulmonary disease. Needs and opportunities. Am J Respir Crit Care Med 2003;167:1142-9.

26. Marsh SE, Travers J, Weatherall M, et al. Proportional classification of COPD phenotypes. Thorax 2008;63:761-7.

27. Hogg JC, Pierce RA. Remodelling of peripheral lung tissue in COPD. Eur Respir J 2008;31:913-14.

\title{
Statins for the treatment of asthma: a discovery well, dry hole or just snake oil
}

\section{Bruce K Rubin}

Until the 1906 Food and Drug Act in the USA, it was common for travelling salesman to move from town to town selling miraculous cures in the form of patent medicines. With the wide spread promotion of Clark Stanley's Snake Oil Liniment, the term "snake oil" became a widely accepted derogatory phrase for ineffective patent medications sold with

Correspondence to: Dr Bruce K Rubin, Wake Forest University School of Medicine, Medical Center Blvd, Winston-Salem, North Carolina 27157-1081, USA; brubin@wfubmc.edu claims for curing an extraordinarily variety of illnesses. ${ }^{1}$

Statins are inhibitors of the 3-hydroxy3-methylglutaryl coenzymes A (HMGCoA) reductase. These are among the most widely prescribed medications in the world today. Statins are dramatically effective, treating hyperlipidaemia and preventing cardiovascular disease, particularly in high risk populations. ${ }^{2}$ Statins have also been shown in the laboratory to have impressive immunomodulatory effects. $^{3}$ These drugs suppress $\mathrm{T}$ helper (Th) 1 cell development and promote Th2 polarisation from CD4 cells in vitro. ${ }^{4}$ Statins act as direct inhibitors of major histocompatibility antigen (MHC) class 2 expression and interferon $\gamma(\mathrm{IFN} \gamma)$ and thus inhibit $\mathrm{T}$ cell activation. ${ }^{5}$

In animal models, statins can ameliorate Th1 inflammatory disorders such as collagen induced arthritis and are being considered as a promising therapy for rheumatoid arthritis. ${ }^{6}$ They have also been shown to be effective in models of autoimmune encephalomyelitis, ${ }^{7}$ inflammatory colitis ${ }^{8}$ and even psoriasis. ${ }^{9}$

There have also been experimental and clinical observations related to the use of statins for the treatment of lung disease. McKay et al showed that high dose simvastatin $(40 \mathrm{mg} / \mathrm{kg})$ attenuated eosinophil driven inflammation in a murine model of ovalbumin induced asthma. This was mediated, at least in part, by suppressing $\mathrm{T}$ lymphocyte secretion of interleukin (IL) 4 and IL5. ${ }^{10}$ Samson et al showed that fluvastatin decreased peripheral blood mononuclear cell proliferation 
production of IL5 and IFN $\gamma$ after both allergen specific and non-specific stimulation. However, in contrast with earlier studies, fluvastatin did not decrease MHC2 expression on dendritic cells or lymphocytes. ${ }^{11}$ More recently, it was reported that in a large matched cohort study, the use of statins was associated with a significantly decreased risk of death from influenza, pneumonia and chronic obstructive pulmonary disease. ${ }^{12}$ In 2136 pulmonary function measurements performed prospectively in 803 elderly men in the Normative Aging Study, statin use attenuated the normal decline in lung function but the size of the beneficial effect was modified by smoking status. ${ }^{13}$

In this issue of Thorax, Imamura and colleagues ${ }^{14}$ report that pravastatin inhibits antigen sensitisation presentation in the lungs of ovalbumin sensitised mice, both when administered simultaneously with ovalbumin sensitisation and after the sensitisation protocol has been completed (see page 44). This appears to be mediated, at least in part, by suppressing IL17 production. Pravastatin also attenuated ovalbumin induced cell proliferation, IL5 production and eosinophilic airway inflammation. On the basis of this, the authors suggest that pravastatin may be a useful therapy for the treatment of asthma. There are a number of caveats that make this interpretation a bit troublesome. The authors acknowledge that experimental ovalbumin induced asthma is very different from human asthma, making it difficult to predict the effects of therapeutic interventions in humans. They acknowledge that the mice were given a large dose of pravastatin $(10 \mathrm{mg} / \mathrm{kg} /$ day $)$ because $2 \mathrm{mg} / \mathrm{kg}$ did not attenuate allergic airway inflammation. Thus the dose administered was more than 30 times that used in humans for the treatment of hyperlipidaemia. In addition, this was a short term study and it is not obvious that the long term use of statins would continue to demonstrate immunomodulation or a nonlinear effect on the immune system.

In fact, there have now been two published clinical trials evaluating the use of statins for the therapy of asthma. In a 1 month randomised placebo controlled trial of simvastatin in 16 subjects with asthma who had all anti-inflammatory medication withdrawn, there was no improvement in asthma symptoms, pulmonary function or measures of asthmatic inflammation, including exhaled nitric oxide, sputum or serum eosinophils, serum $C$ reactive protein and salivary eosinophilic cationic protein, although subjects on the statin did have a significant decrease in serum cholesterol. ${ }^{15}$ There were similar findings in an 8 week duration randomised clinical trial of $40 \mathrm{mg} /$ day atorvastatin added to inhaled corticosteroids (ICS) compared with ICS alone in 54 adults with allergic asthma. ${ }^{16}$ The authors of these studies concluded that statins were ineffective for the short term therapy of asthmatic inflammation.

Considering what is practical, we already have extremely effective medications for the treatment of allergic asthma in the form of ICS. For most patients the problem does not appear to be that ICS do not work, but rather that they are often not taken as prescribed. ${ }^{17}$ It does not appear that adding a statin to an appropriate dose of ICS would provide any additional benefit for patients with asthma.

Thus we are left with exciting data but a nagging dilemma. In the oil exploration industry, a discovery well is drilled as the first oil well in a new field to reveal the extent of oil or gas deposits. These authors appear to have struck oil by demonstrating a dose dependent and reproducible suppression of allergic inflammation after administration of pravastatin to ovalbumin sensitised mice. Whether this turns out to be a discovery of tremendous clinical importance or it quickly plays out to a dry well, only further clinical trials will tell for sure. Until then, it is too early to abandon tried and true remedies for allergic asthma for what potentially could be just another snake oil panacea.

Competing interests: None.

Thorax 2009;64:4-5. doi:10.1136/thx.2008.106757

\section{REFERENCES}

1. Morris W, Morris M. Morris Dictionary of Word and Phrase Origin, 2nd Edn. New York: Harper \& Row, 1988:535.

2. Bhatnagar D, Soran H, Durrington PN. Hypercholesterolaemia and its management. BMJ 2008;337:a993

3. Greenwood J, Steinman L, Zamvil SS. Statin therapy and autoimmune disease: from protein prenylation to immunomodulation. Nat Rev Immunol 2006;6:35870.

4. Hakamada-Taguchi R, Uehara $Y$, Kuribayashi $\mathrm{K}$, et al. Inhibition of hydroxymethylglutaryl-coenzyme A reductase reduces Th1 development and promotes Th2 development. Circ Res 2003;93:948-56.

5. Kwak B, Mulhaupt F, Myit S, et al. Statins as a newly recognized type of immunomodulator. Nat Med 2000;6:1399-402.

6. Paraskevas KI. Statin treatment for rheumatoid arthritis: a promising novel indication. Clin Rheumatol 2008:3:281-7.

7. Youssef S, Stuve 0, Patarroyo JC, et al. The HMG$\mathrm{CoA}$ reductase inhibitor, atorvastatin, promotes a Th2 bias and reverses paralysis in central nervous system autoimmune disease. Nature 2002;420:78-84.

8. Lee JY, Kim JS, Kim JM, et al. Simvastatin inhibits NF-kappaB signaling in intestinal epithelial cells and ameliorates acute murine colitis. Int Immunopharmacol 2007;7:241-8.

9. Späh F. Inflammation in atherosclerosis and psoriasis: common pathogenic mechanisms and the potential for an integrated treatment approach. Br J Dermatol 2008;159(Suppl 2):10-17.

10. McKay A, Leung BP, Mclnnes IB, et al. A novel anti-inflammatory role of simvastatin in a murine model of allergic asthma. J Immunol 2004;172:2903-8.

11. Samson KT, Minoguchi K, Tanaka A, et al. Inhibitory effects of fluvastatin on cytokine and chemokine production by peripheral blood mononuclear cells in patients with allergic asthma. Clin Exp Allergy 2006;36:475-82.

12. van Gestel YR, Hoeks SE, Sin DD, et al. Effect of statin therapy on mortality in patients with peripheral arterial disease and comparison of those with versus without associated chronic obstructive pulmonary disease. Am J Cardiol 2008;102:192-6.

13. Alexeeff SE, Litonjua AA, Sparrow D, et al. Statin use reduces decline in lung function: VA Normative Aging Study. Am J Respir Crit Care Med 2007;176:742-7.

14. Imamura M, Okunishi $\mathrm{K}$, Ohtsu $\mathrm{H}$, et al. Pravastatin attenuates allergic airway inflammation by suppressing antigen sensitisation, interleukin 17 production and antigen presentation in the lung. Thorax 2009:64:44-49.

15. Menzies D, Nair A, Meldrum KT, et al. Simvastatin does not exhibit therapeutic antiinflammatory effects in asthma. J Allergy Clin Immunol 2007;119:328-35.

16. Hothersall EJ, Chaudhuri R, McSharry C, et al. Effects of atorvastatin added to inhaled corticosteroids on lung function and sputum cell counts in atopic asthma. Thorax 2008;63:1070-75.

17. Rubin BK. What does it mean when a patient says, "My asthma medication isn't working?" Chest 2004:126:972-81. 